\title{
The enhanced catalytic dissociation of adsorbed hydrogen containing molecules
}

\author{
V.G.Litovchenko, A.A.Efremov \\ Institute of Semiconductor Physics \\ of the National Academy of Sciences of Ukraine, \\ 45 Nauki Str., 252028 Kyiv, Ukraine
}

Received April 21, 1998

\begin{abstract}
Some general conceptions and mechanisms of dissociative adsorption and catalysis are analyzed. The role of such factors as electronic shell configurations of isolated atoms, crystalline structure of the surface, local structural irregularities and defects, orientation of the surface bonds, dimensional effects, the presence of foreign atoms in the local atomic environment as well as the local symmetry of adsorption center are discussed. These considerations were used in developing the program for computer simulation of the process. The catalytic properties of $\mathrm{PdCu}_{\mathrm{x}}$ surface alloys are analyzed using computer modelling and thus the enhancement of dissociative adsorption of $\mathrm{H}_{2}$ for such a system is predicted. The experimental data, demonstrating the enhancement of sensitivity of MIS sensor with CuPd electrode in comparison with the pure Pd electrode, are presented.
\end{abstract}

Key words: dissociative adsorption, computer simulation, catalysis, gas detection, surface alloys

PACS: 82.65.JV, 82.20.W, 82.30.Nr, 33.15.F

\section{Introduction}

The problems of enhancing the catalytic activity of the surface solids were discussed for a long time both from theoretical and applied points of view $[1-5]$. The classical catalytic systems ordinarily use the transition metals in different modifications, mainly as a microporous composite, polycrystalline substrates, sometimes as monocrystalline samples. The most novel approach in this direction is using the composite systems consisting of either the film of transition metal covered by ultrathin layer of another noble metal [6] or submonolayer coatings of catalytically active atoms on inactive substrates $[7,8]$.

The important and specific case of a catalytic process is a dissociative adsorption of molecules leading, in the end, to intensive surface reactions between atomic parti- 


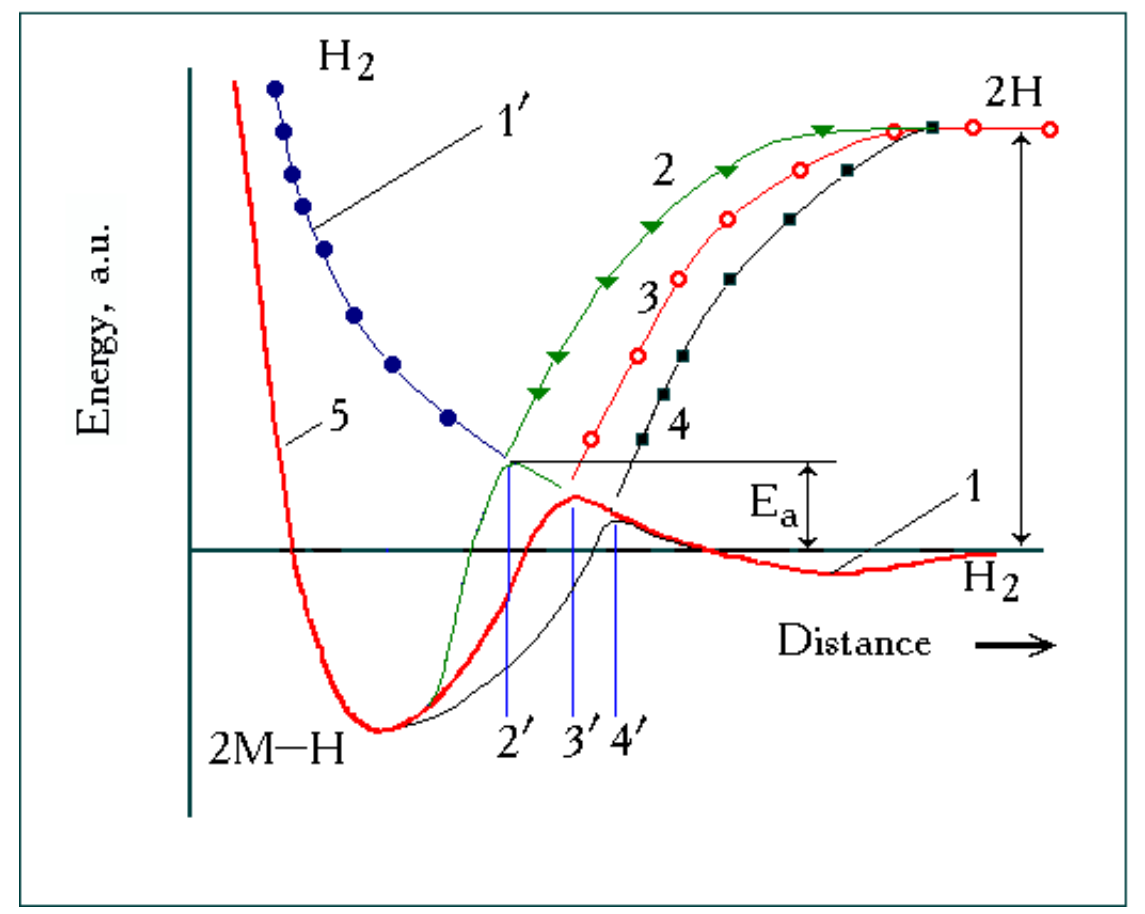

Figure 1. 1D presentation of potential barrier when $\mathrm{H}_{2}$ molecule interact with the metal surface. $1,1^{\prime}$ is a repulsive curve for molecule, 1 is a pre-chemisorption state. 2, 3, 4 are attractive curves for atomic hydrogen for $\mathrm{Cu}, \mathrm{Pd}$ (declined bonds) and Pd (normal bonds) correspondingly 2', 3', 4' are respective barriers; 5 is a repulsive curve for bounded $\mathrm{H}_{\mathrm{a}}$

cles. This process also plays one of the key roles in gas detection by metal-insulatorsemiconductor (MIS) sensors with a catalytically active (Pt, Pd etc.) metallic layer. Numerous experimental data show that catalytic yield of a reaction depends strongly on both the structure and on the composition of the catalyst surface [1-5]. In spite of such noble metals as $\mathrm{Cu}, \mathrm{Au}$ of $\mathrm{Ag}$ are usually bad catalysts, the use of surface alloys consisting of transition and noble metals instead of a pure transition metal leads in many cases to more pronounced catalytic properties. Even isolated atoms deposited on the inert surface may demonstrate in some cases a very high catalytic activity [8]. Therefore, such a fundamental factor as an electron shell configuration of atoms, together with local short range order and crystalline structure at the surface are simultaneously important for catalytic behaviour of solids. At least, two factors, which were not enough analyzed, have to be considered in this connection: (i) peculiarities of chemical bonds (their rehybridization, orientation, directness, weakening, reattachment etc.) on the surface, where actually the catalytic processes take place. (ii) the effect of the active doping atoms (ligands), which are present in the local vicinity of transition metal atom (up to the forming of alloys) on the catalysis reaction event.

In the present paper we shall discuss some general conceptions and mechanisms of dissociative adsorption and catalysis starting from electronic configurations of atoms being part of an active adsorption center. Then, we shall consider the role both of the 
structural and impurity peculiarities of the surface in these processes. More detailed analysis of the catalytic properties of $\mathrm{PdCu}_{\mathrm{x}}$ surface alloy will be presented. We shall study dissociative adsorption of hydrogen at the active centers of such a surface in the framework of both the macroscopic and the microscopic models using two variants of computer modelling. In the former case the model describing the processes in MIS gas sensors with $\mathrm{Pd}$ (or $\mathrm{PdCu}$ ) electrode will be considered. In the latter case the computer simulation will be applied to dissociative adsorption itself. We shall show that $\mathrm{CuPd}$ alloy is, in some extent, the optimum catalyst for decomposition of hydrogen containing molecules. In conclusion, the experimental data demonstrating the enhancement of sensitivity of MIS gas sensor with $\mathrm{Pd}$ electrode, covered with an ultra-thin $\mathrm{CuPd}$ alloy film, in comparison with pure $\mathrm{Pd}$ film will be presented.

\section{Qualitative consideration of the adsorbo-catalytic centers on the transition metals}

\subsection{Configurations of the electronic shells in isolated atoms and their ef- fect on adsorption}

To understand the role of different factors listed above effecting the interaction of the molecule with the surface it is useful to analyze a one-dimensional potential diagram of this process (in the case of $\mathrm{H}_{2}$ ) shown in figure 1 . The resulting shape of the potential energy curve is determined by the superposition of three different branches:

(i) the curve, describing the repulsion of a nondissociated $\mathrm{H}_{2}$ molecule at its approaching the center (1-1', figure 1$)$;

(ii) the curve, corresponding to the repulsion of isolated atom(s) within a potential well after dissociation of the molecule (5, figure 1$)$;

(iii) the curve, corresponding to the attraction between the active center and the atomic particle outside the well $(2,3,4$, figure 1$)$.

The intersection of the first and the second potential curves ("cross-over") determines both position and height of a potential barrier for dissociative adsorption, and superposition of the $2^{\text {nd }}$ and the $3^{\text {rd }}$ potential curves gives us the depth and the position of the potential well for the captured atom. In this qualitative model the dissociation takes place near the cross-over point. One may derive that the closer the molecule can approach the surface without dissociation, the higher proved to be the potential barrier for adsorption. This fact is demonstrated by a comparison of the attractive curves 2-2', 3-3', 4-4' in figure 1 . Therefore, the reason for good catalytic properties of a definite group of transition metals is participation in the creation of the chemisorption bonds d-electron orbitals. These orbitals, in comparison with apparently even more strong bonding $\mathbf{s}, \mathbf{p}$ or $\mathbf{s p}$-hybrid orbitals, are long-range acted orbitals (curve 4, figure 1). As a result they form a relatively small barrier for adsorption, the activation energy for catalytic processes $\mathrm{E}_{\mathrm{a}}$ decrease drastically, 
and the cross-section of the reaction of catalytic decomposition is highly increased. Such surface atoms as Ni, Pd, Pt (as well as W, Mo), whose long-ranged d orbitals interact with $\mathrm{H}_{2}$-molecule at relatively long distances (curve 3,4) can form the centers for easy or spontaneous adsorption. On the contrary, for $\mathrm{Cu}, \mathrm{Ag}$, or $\mathrm{Au}$ with s-orbitals the adsorption of $\mathrm{H}_{2}$ is practically missing (curve 2).

\subsection{The electronic transitions in the system "molecule-active center": the role of the local structure irregularities and defects}

Dissociative adsorption on the active centers at the surface may be treated from somewhat another point of view, namely as a result of electron transitions from atoms of a substrate to the antibonding orbital of a molecule (dissociation) and subsequent transition of electrons from molecule constituents to the empty orbitals of surface atoms (chemisorption). When $\mathrm{H}_{2}$ molecule moves to the surface, the nonequivalent shifting of the splitted energy levels takes place: antibonding (empty) level of $\mathrm{H}_{2}\left(1 \mathrm{~s}^{2}\right)$ shifts down, but bonding one of $\mathrm{Cu}$ and $\mathrm{Ni}(\mathrm{Pt}) 4 \mathrm{~s}^{2}\left(6 \mathrm{~s}^{1}\right)$ shifts up. If outer electronic shells of surface atoms are formed by isotropic s-orbitals, the main role in the process is played by the collective properties of electronic gas, namely the intersection of antibonding level of the molecule with the Fermi level of the metal. The latter results in the crossover at a definite small distance only. On the contrary, in the case of more localized, directed and long-range acted d-orbitals (Ni$3 \mathbf{d}$, Pt-6d), the intersection takes place at the much longer distances, because the mentioned electron transfers may occur from the quasi-local state above Fermi-level. According to figure 1 the dissociative chemisorption is accompanied by the overtaking of a small activation barrier. These considerations enable us to explain the role of various local structural irregularities and defects on the surface of a transition metal in a remarkable increase of the chemisorption of $\mathrm{H}_{2}, \mathrm{O}_{2}$ and $\mathrm{O}$-containing molecules. Dislocations, steps, atomic layer terraces, distorted and weakened bonds, surface substructures $(2 \times 1,7 \times 7$ etc. $)$, reoriented surface domains with unsaturated boundary bonds in polycrystalline $\mathrm{Pt}, \mathrm{Pd}, \mathrm{Ni}$ films and so on, can act as chemical active unsaturated surface radicals determining the increase of a catalytic yield. They not only give addition places for adsorption, but also form a lot of quasilocal levels, which became responsible for the electron transitions mentioned.

\subsection{Active centers: the role of crystalline structure in their atomic environ- ment on the surface}

The effect of the crystal plane structure and crystal orientation was demonstrated in many works. As far as the more compact surfaces have got a less free energy (surface (100)), Pt(111) plane was preferably used in the catalytic reaction. In particular, at $\mathrm{HN}_{3}$ oxidation the (111) plane continually reconstructed to (100) plane due to the heating by a surface chemical reaction. In general, the plane with higher indexes has a tendency to enhancing the catalytic reaction.

It is possible to analyze the catalytic processes for $\mathrm{H}_{2}$ adsorption within the framework of "surface model" $[1,5]$. At the $\mathrm{H}_{2}$ molecule moving to a surface, at 
small distances, the chemical potential of electrons has to coincide with the metal Fermi surface. To satisfy this condition the electron transition of H-electron to metal has to be realized. Theoretical analysis (for W $[1] \mathrm{Pt}[5,9,10]$ ) shows that only the nearest d-orbital, directed to s-orbitals of $\mathrm{H}$ adatom, takes part in forming the adsorption bonds. Besides, directed along the plane, and a weaker interaction of $\mathrm{H}$-adatom with the other surface atoms of transition metal takes place as well. Just this, crystalline order dependent interaction, determines the important peculiarities of surface molecules comparative to the bulk. Minimum of energy occurs under bonding of the adatom $\mathrm{H}$ with four (for (100) plane) d-orbitals of the surface atoms of the substrate. The configurations with 2 or 1 d-orbitals are less stable, but still probable for the surface as well, because of a large dispersion of energy levels for the near-to-surface H-atom. Hence, resonance tunnelling of the electron at the forming of s-d bounds becomes possible in this configuration.

\subsection{Active centers: the role of the orientation of surface bonds}

The orientation of unsaturated surface bonds is very important for surface reactions. This parameter is strongly dependent on the type of crystalline structure. In a set of theoretical works (see [1]) the role of orientation of d-orbitals has been analyzed. Catalytic properties can be classified according to the degree of orientation of the free d-orbitals. Of course, in addition to this factor, it is also necessary to take into account the number of free d-orbitals and the degree of their directness (i.e., number of d-shells) [1,3]:

1) normal to-surface directed nonoccupied d-orbitals (Mo,W);

2) large-angle directed $\left(45^{\circ}, 36^{\circ}\right)(\mathrm{Pd}, \mathrm{In}, \mathrm{Ru}, \mathrm{Os}, \mathrm{Re}, \mathrm{Te})$;

3) low-angle, partly filled d-orbitals (Fe, Co, Ni, Pd, Pt);

4) fully-occupied d-shells with asymmetric properties (Zn, Ge, Cd, In, Sn, Pb).

It was found [1] that the normally oriented d-orbitals are usually more suitable for adsorption, because interaction of the molecule with declined bonds requires its more sufficient approach to the surface. Another factor is a geometric correspondence between positions of the atoms in the molecule and positions of the end points of surface dangling bonds. Hence, in some special cases declined bonds proved to be more favourable for a catalytic reaction.

\subsection{Active centers on the surface of small clusters}

The structure of small clusters is typical of microcrystalline composites and nonepytaxial films. In this case we have got a substrate, which is intermediate between insulated molecules and a bulk condensed matter. At growth, the size of the cluster increases and the energy of ionization decreases up to the value of workfunction (for example, for $\mathrm{Ag}$ from $7.5 \mathrm{eV}$ to $4.5 \mathrm{eV}$ ). On the contrary, the electron affinity 
increases, as well as the average energy of the chemical bond does $(2.96 \mathrm{eV}$ for metallic $\mathrm{Ag})$. Surface energy is also remarkably larger for the smallest clusters $(1-5 \mathrm{~nm})$. A very important point is that for a small cluster, electron orbitals have got specific features. In particular, high catalytic properties of Pt could not be explained within the framework of electron configuration of insulating atoms due a complete filling of d-shell (10d electrons), hence, the lower empty orbitals of Pt could be s-orbitals. But even in the simplest clusters 2Pt, the s-orbitals, being diffuse overlapped with each other, form a symmetric molecular orbital with the small bonding energy. The d-orbital electrons, now having a higher energy can transfer to this empty orbital, and in such a way, lead to the vacating of some d-orbitals. The number of such free d-orbitals increases at the increase of the size of clusters. The same process also takes place for the other transition elements even for the case, when d-shell is not completely occupied (as Ni, Pt). Therefore, for large clusters or bulk solid state the combination of the low-energy free d-orbitals (which is necessary to form long-range chemical bonds, for effective catalytic properties) with a high energy occupied the antisymmetric combination of d-orbitals $\left(t_{2 g}: d_{x y}, d_{x z}, d_{y z} ; e_{g}: d_{x} 2_{-y} 2, d_{z} 2\right)$, which is strongly directed, and promote the overlapping with the orbitals of the adsorbed molecules. This mechanism relates to the so called "catalytic stereochemistry" and is usually revealed for $\mathrm{Pt}, \mathrm{Pd}$, Ni etc.

\subsection{Active centers: the role of the foreign atoms in the local atomic envi- ronment}

There is, however, quite another class of catalytically promoted reactions which are practically insensitive to the structure of catalysts but only to its composition.

Even for structural-sensitive reactions, the emerging of some types of foreign atoms (ligands) in the local environment of the adsorption center proved to be more effective for the control of catalytic activity, than structural transformations $[1,3,4,5]$. There are at least four different mechanisms of the impurity effecting the catalytic activity of transition metals.

(i) First of all, the microcluster, which is formed on (or under) the surface from an active atom and surrounding ligands may provide a more exothermic reaction than in ordinary case.

(ii) Some peculiarities of electron transfer between the central atom of the active complex and ligands may effect the degree of d-orbital filling. The main idea for using the surface alloys (or highly-doped transition metals) consists in the transformation, (like in the case of $\mathrm{Pd}$ ) of the completely filled d-shells for elements of $1 \mathrm{~B}$ group $(\mathrm{Cu}, \mathrm{Ag}, \mathrm{Au})$ and $2 \mathrm{~B}(\mathrm{Zn}, \mathrm{Cd}, \mathrm{Hg})$ into partly unfilled d-shells. The latter takes place due to overlapping with unfilled ( $\mathrm{Pd}, \mathrm{Ni}$, as well as Ro, W, Mo etc.) orbitals, and provides new systems with a high efficiency and stability against oxidation and other undesirable aging processes. The most interesting are the systems consisting of a transition metal doped with copper. 
(iii) Replacement of the intrinsic atoms in close vicinity of the center atom by foreign atoms changes the local symmetry of the center, the character of its bounding with the nearest neighbours as well as the orientation of surface dangling bonds. For example, the presence of oxygen results in such bonds reattachment when d-electrons prefer to be transferred to p-orbitals of the neighbours, rather than on the antibonding orbital of the adsorbing molecule $[2,11]$. On the contrary, the presence in the local atomic environment of a relatively electropositive elements (e.g. $\mathrm{Cu}$ in $\mathrm{Pd}$ ) gives some accumulation of electron density on d-orbital of $\mathrm{Pd}$ and the increase of its directness. The model for describing the catalytic activity of $\mathrm{Cu}_{\mathrm{x}} \mathrm{Pd}$ complexes based on this effect will be theoretically considered below.

(iv) The next mechanism consists in long range Coulomb interaction. The difference in electronegativities $(1.8 \mathrm{eV}$ for $\mathrm{Cu}$ and $2.1-2.3 \mathrm{eV}$ for $\mathrm{Pd}, \mathrm{Pt}$ ) leads to some $\mathrm{Pd}-\mathrm{Cu}$ bond polarization within the $\mathrm{Cu}_{\mathrm{n}} \mathrm{Pd}_{\mathrm{m}}$ cluster with the accumulation of a positive charge on $\mathrm{Cu}$. The resulting electrostatic field transforms the potential diagram of the center just outside the main potential well (figure 1 ) in such a way that the residence time of a molecule in pre-chemisorption state increases.

\subsection{The local symmetry of adsorption centers: topo- and stereochemistry aspects}

Catalytic processes for surface complexes (including H-containing molecules) have also got some important features, because of their discrete electron energy spectrum. For instance, in the case of surface reaction with organic molecules the orbitals have a tendency to conservation of the symmetry factor during chemical transformations. The reaction is symmetry-permitted, when the symmetry of all bonding orbitals of the reagents coincides with the symmetry of the final product. A catalyst can promote the reaction, transforming the symmetry-forbidden reaction for gas, into a symmetry-permitted reaction on the surface by way of forming the subsequent adsorbed particles with a suitable symmetry. In particular, some unbonding d-electrons can transfer to the surface molecule, and then transfer on the d-orbitals of the metal surface with the other symmetry. Another way is forming a surface radical, having another origin than the molecules in a gaseous phase. An example is the case of $\mathrm{H}_{2}+\mathrm{O}_{2}$ reaction on the surface, which for a gaseous state is symmetry-forbidden due to noncoexistance of the pair-degree of orbitals, but dissociation of $\mathrm{H}_{2} \rightarrow \mathrm{H}+\mathrm{H}$ on the surface permits the reaction $\mathrm{O}_{2}$ with hydrogen [3]. A very important particular case of catalytic enhancement is based on the coinciding of molecular symmetry of the final product of the reaction with the symmetry of the local atomic arrangement on the surface. A typical example is a hydrocyclization reaction on n-heptan to toluol on $\mathrm{Pt}(111)$ surface with hexagonal symmetry. 


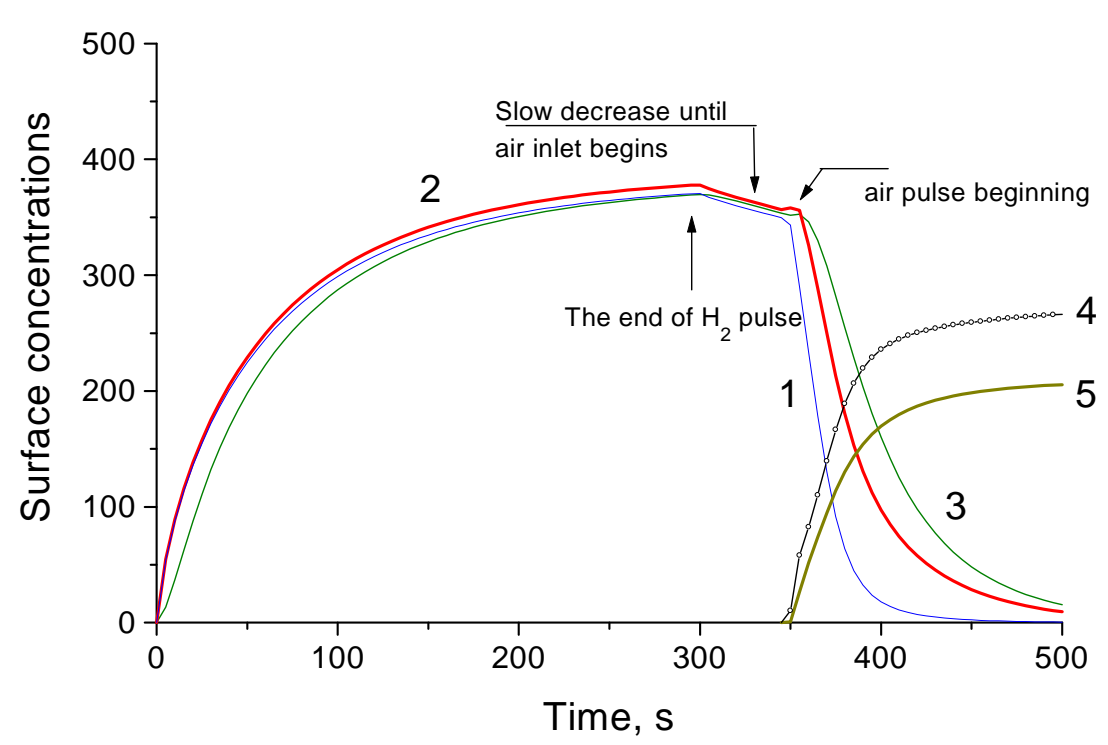

Figure 2. Theoretical calculation of concentrations of atomic hydrogen $\mathrm{H}_{\mathrm{e}}$, oxygen $\mathrm{O}_{e}$ and hydroxyls $\mathrm{OH}_{e}$ at the external metallic surface, and of hydrogen captured at the metal-insulator interface $\left(\mathrm{H}_{\mathrm{i}}\right)$ of the MIS gas sensors under the action of the sequence of $\mathrm{H}_{2}$ and air pulses: $1-\mathrm{H}_{\mathrm{e}} ; 3-\mathrm{H}_{\mathrm{i}} ; 4-\mathrm{O}_{\mathrm{e}} ; 5-\mathrm{OH}_{\mathrm{e}}$; curve 3 is the concentration of hydrogen dissolved in the bulk of the layer.

\section{Modelling and simulation of the adsorption-desorption pro- cesses}

We have applied the above qualitative consideration to the analysis of the catalytic properties of $\mathrm{PdCu}_{\mathrm{x}}$ surface alloys by means of computer modelling. We have used two different approaches to the modelling of the $\mathrm{H}_{2}$ adsorption processes. The first is the computation of a MIS sensor response under hydrogen action $[2,11]$. The second approach in the modelling is the direct simulation of $\mathrm{H}_{2}$ molecule behaviour during its adsorption on the pair of surface centers.

\subsection{The modelling of adsorption/desorption processes at the surface of the active metal layer in MIS gas sensors.}

The main physical processes, which occur in MIS gas sensor with catalytic metal layer may be outlined as follows $[2,11]$. At the beginning, on the external surface of the active metallic layer, the dissociative adsorption and desorption of $\mathrm{H}_{2}$ molecules takes place. Then, atomic hydrogen is transferred through the film to the metalinsulator interface, where the internal adsorption and polarization of the atoms takes place. The result of such polarization is the shift of the flat-band voltage $\left(\Delta V_{\mathrm{FB}}\right)$ of the MIS structure, which may be also calculated and compared with the results of $\mathrm{C}-\mathrm{V}$ measurements. These processes have been considered within the framework of a chemical kinetic approach. The system behaviour was described by a system of differential equations for surface $\left(\mathrm{n}_{\mathrm{ke}}\right)$ and interface $\left(\mathrm{n}_{\mathrm{ke}}\right)$ concentrations of $\mathrm{k}$-th 
atom:

$$
\begin{aligned}
\mathrm{d} n_{\mathrm{ke}} / \mathrm{d} t & =R_{\mathrm{k}}\left(n_{1 \mathrm{e}}, n_{2 \mathrm{e}}, \ldots, n_{\mathrm{ke}}, \ldots\right)+c_{\mathrm{k}} P_{\mathrm{m}} N_{\mathrm{ef}}^{\mu}-d_{\mathrm{k}} n_{\mathrm{ke}}^{\mu}-\mathrm{d}_{\mathrm{k}} n_{\mathrm{ki}} / \mathrm{d} t \\
\mathrm{~d} n_{\mathrm{ki}} / \mathrm{d} t & =K_{\mathrm{k}} n_{\mathrm{ke}} N_{\mathrm{if}}-S_{\mathrm{k}} n_{\mathrm{ki}} N_{\mathrm{ef}} .
\end{aligned}
$$

Here adsorption and desorption are determined by a set of adsorption/desorption coefficients $\mathrm{c}_{\mathrm{km}}$ and $\mathrm{d}_{\mathrm{km}}$ for molecules and by the order adsorption reaction $\mu$ (multicentered dissociative, or monocentered). These parameters are functions of the ambient temperature. The further process consists in the reactions at the external surface between the products of dissociation of the molecules. The rates of these surface reactions are described by a nonlinear function $\mathrm{R}_{\mathrm{k}}\left(\mathrm{n}_{1 \mathrm{e}}, \mathrm{n}_{2 \mathrm{e}}, \ldots, \mathrm{n}_{\mathrm{ke}}, \ldots\right)$ according to the theory of absolute chemical reaction rates.

Here, power $\mu$ is equal to 2 for dissociative adsorption (associative desorption) of a molecule containing the atom of $\mathrm{k}$-th type. $\mathrm{N}_{\text {if }}$ and $\mathrm{N}_{\text {ef }}$ are the numbers of centers available for adsorption, i.e. free from adsorbed particles:

$$
N_{\mathrm{ef}}=N_{\mathrm{e}}-\sum_{\mathrm{k}} \nu_{\mathrm{k}} n_{\mathrm{ke}}, \quad N_{\mathrm{if}}=N_{\mathrm{i}}-\sum_{\mathrm{k}} \nu_{\mathrm{k}} n_{\mathrm{ki}} ;
$$

in its turn $\nu_{\mathrm{k}}$ is a number of centers occupied (or blocked) by one captured particle.

The parameters $K_{k}$ and $S_{k}$ are forward and reverse transport coefficients for each component which can move through the layer. Calculated response of a MIS sensor on a pulse of hydrogen, followed by a pulse of oxygen is shown in figure 2. Here chemical reactions between atomic $\mathrm{H}$ and $\mathrm{O}$ (resulting in $\mathrm{OH}$ formation and $\mathrm{H}_{2} \mathrm{O}$ desorption) on the external surface are taken into account.

The comparison of the theoretical and experimental responses of the sensor on the gas pulses makes it possible to derive the values of phenomenological coefficients related to adsorption/desorption process itself. Hence, the reasonable estimations of such microscopic parameters as the depth and width of potential well and the height of barrier for adsorption have been done [2].

Herein below we shall consider in more details the second approach in the modelling.

\subsection{The computer simulation of dissociative adsorption at the $\mathrm{Cu}_{\mathrm{x}} \mathrm{Pd}$ surface}

The method, which we have used here may be treated as a version of molecular dynamics or molecular mechanics approaches. In the simulations we compare dissociative adsorption on the surface of pure palladium and on $\mathrm{PdCu}_{\mathrm{x}}$ surface alloy, which may be formed, in particular, by the growth of ultra-thin copper films on the palladium. The deposition of metals on metals present an alternative approach to the studies of alloy surfaces and a way of producing controllable compositions more readily. Such surfaces in some cases exhibit configurations and properties at bulk alloy surfaces. This type of surface alloys and composites has become an area of a considerable part of the current research, because of their fundamental interests in catalysis as well as due to their importance in a novel device fabrication for 
coating and sensor development. The aim of simulations is to explain the enhanced sensitivity of (MIS) gas sensors with the active $\mathrm{CuPd}$ layer.

The general schema of the process is shown in figure 3 . Here a two atomic molecule (e.g. $\mathrm{H}_{2}$ ) moves toward the group of atomic force centers, which represent atoms of $\mathrm{Pd}$ or/and $\mathrm{Cu}$ at some fragment of the surface. The classical Hamiltonian for such a system may be presented as follows:

$$
H\left(\mathbf{p}_{1}, \mathbf{p}_{2}, \mathbf{r}_{1}, \mathbf{r}_{2}\right)=\sum_{\mathrm{i}} p_{\mathrm{i}}^{2} / 2 m+\sum_{\mathrm{i}} \sum_{\mathrm{k}}^{\mathrm{N}} U_{\mathrm{ik}}\left(\mathbf{r}_{\mathrm{i}}, \mathbf{R}_{\mathrm{k}}, \Theta_{\mathrm{k}}\right)+V_{\mathrm{m}}\left(\left|\mathbf{r}_{1}, \mathbf{r}_{2}\right|\right),
$$

here $\mathbf{p}_{1}, \mathbf{p}_{2}, \mathbf{r}_{1}, \mathbf{r}_{2}$ are momentums and radius vectors of the atoms, $\mathrm{V}_{\mathrm{m}}\left(\left|\mathbf{r}_{1}, \mathbf{r}_{2}\right|\right)$ is interatomic interaction in the molecule. For this purpose we use the Morse potential:

$$
V_{\mathrm{m}}(r)=D_{\mathrm{o}} \exp \left(-\left(r-r_{\mathrm{o}}\right) / L_{\mathrm{D}}\right)\left(\exp \left(-\left(r-r_{\mathrm{o}}\right) / L_{\mathrm{D}}\right)-2\right)
$$

where $D_{o}$ is a dissociation energy of the molecule, $r_{o}$ is an equilibrium interatomic distance, $\mathrm{L}_{\mathrm{D}}$ is an effective width of the respective potential well, determining both the oscillation frequency $\omega_{\mathrm{m}}=\left(1 / \mathrm{L}_{\mathrm{D}}\right)\left(2 \mathrm{D}_{\mathrm{o}} / \mathrm{m}\right)^{1 / 2}$ and the maximum possible oscillation amplitude. $\mathrm{U}_{\mathrm{ik}}\left(\mathbf{r}_{\mathrm{i}}, \mathbf{R}_{\mathrm{k}}, \Theta_{\mathrm{k}}\right)$ describes the interaction between $\mathrm{i}$-th $(\mathrm{i}=1,2)$ atom in the molecule and $k$-th atomic force center $(k=1, \ldots, N)$ located at point $\mathbf{R}_{\mathrm{k}}$. The angle $\Theta_{\mathrm{k}}$ according to the previous considerations corresponds to the orientation of the d-orbital as to the surface.

It should be emphasized that the surface of potential energy $U_{i k}\left(\mathbf{r}_{i}, \mathbf{R}_{k}, \Theta_{k}\right)$ has quite different view for a whole molecule (curve 1, figure 1) and for a pair of isolated hydrogen atoms (curve 2, figure 1). As it is obvious from figure $1, \mathrm{H}_{2}$ molecule never be captured by the chemisorption potential well and should be reflected by the surface. On the other hand, the atoms after the molecule dissociation cannot leave the surface of the solid being isolated. These two potential surfaces intersect each other forming the potential barrier for dissociative adsorption. For $U_{i k}\left(\mathbf{r}_{i}, \mathbf{R}_{k}, \Theta_{k}\right)$ in the case of dissociative adsorption we have used analytic approximation, giving the anisotropic potential well with the depth $\mathrm{W}_{\mathrm{o}}$ and barrier $\mathrm{E}_{\mathrm{a}}$ shown in figure 4 . The cross-section of this well along the bond direction corresponds to the curve 1 in figure 1. This shape of the potential surface was used only when dissociation took place in the vicinity of the cross-section point. Otherwise, a pure repulsive $\sim r^{-n}$ potential for molecule was chosen. The respective equations of motion for the molecule in this two-sheet potential field have been solved numerically using a combined 4th order Runge-Kutt-Adams method. The source code has been written in $\mathrm{C}++$ programming language. Windows Application executable file has been obtained with Microsoft Visual $\mathrm{C} / \mathrm{C}++$. The program permits us to change the parameters of the wells, barriers and orientation angles of the bonds.

The interaction of the molecule with five atomic force centers was considered at different initial translational kinetic energies of the molecule and its vibrational excitations. Though the rotational movements may also be included in the model, their role was not studied in detail. Pd atoms were modeled by anisotropic and extended ellipsoid-like potential wells with the barrier depending on the well orientation. On the contrary, copper atoms were represented by practically isotropic 
a)
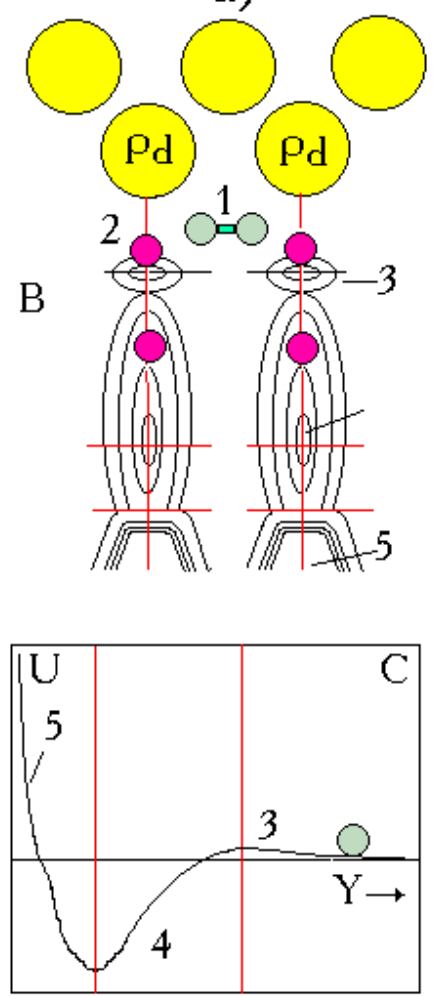

b)

A<smiles>c1ccccc1</smiles><smiles>C1=CCCC=1</smiles>

Pd

$\mathrm{Pd}_{\mathrm{d}}$

B<smiles>OO[AlH]</smiles>

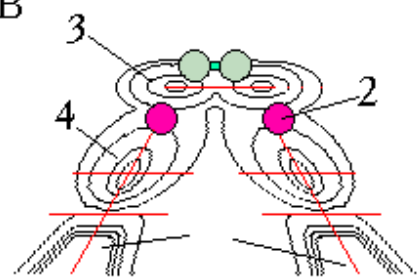

B
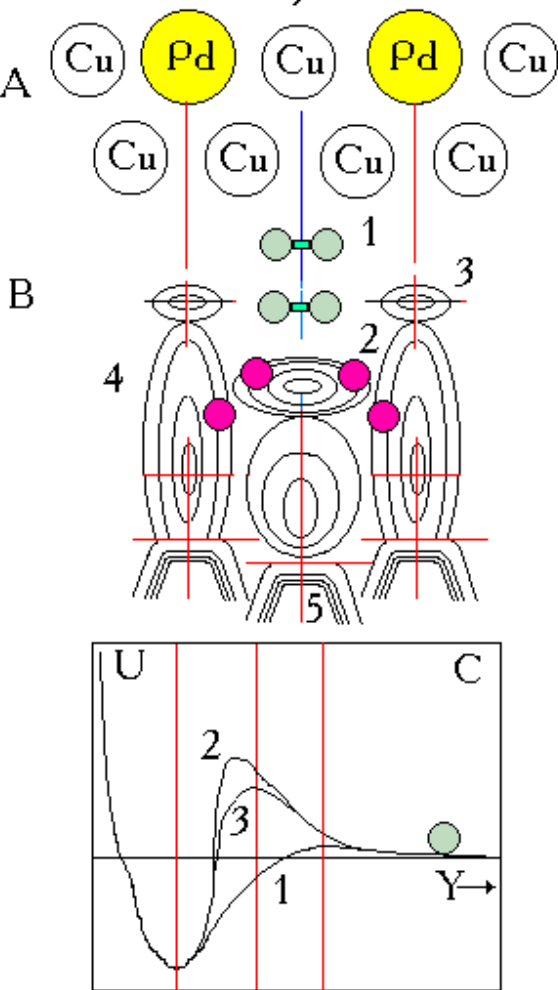

Figure 3. The interaction of $\mathrm{H}_{2}$ molecule with different types of atomic force centers, which simulate the different types of surfaces (a,b and c). a) Pd surface with normal orientation of d-orbitals; b) the same with declined orientation of d-orbitals; c) The case of the surface of $\mathrm{Cu}_{3} \mathrm{Pd}$ alloy. A) Atoms at the surface (top view, XZ plane); B) The 2D map of the potential energy for atomic force centers and the movement of the atomic particles during the adsorption process according to modelling (XY plane cross-section): 1 is a hydrogen molecule, 2 is an atomic hydrogen after dissociation (indicated positions correspond to different stages of the process), 3 is a barrier for adsorption, 4 is a potential well for the captured hydrogen (the depth of the well relates to $\mathrm{Pd}-\mathrm{H}$ bond energy), 5 is a repulsive part of the atomic potential. C) Respective one-dimensional potential curve along the normal to the surface. 


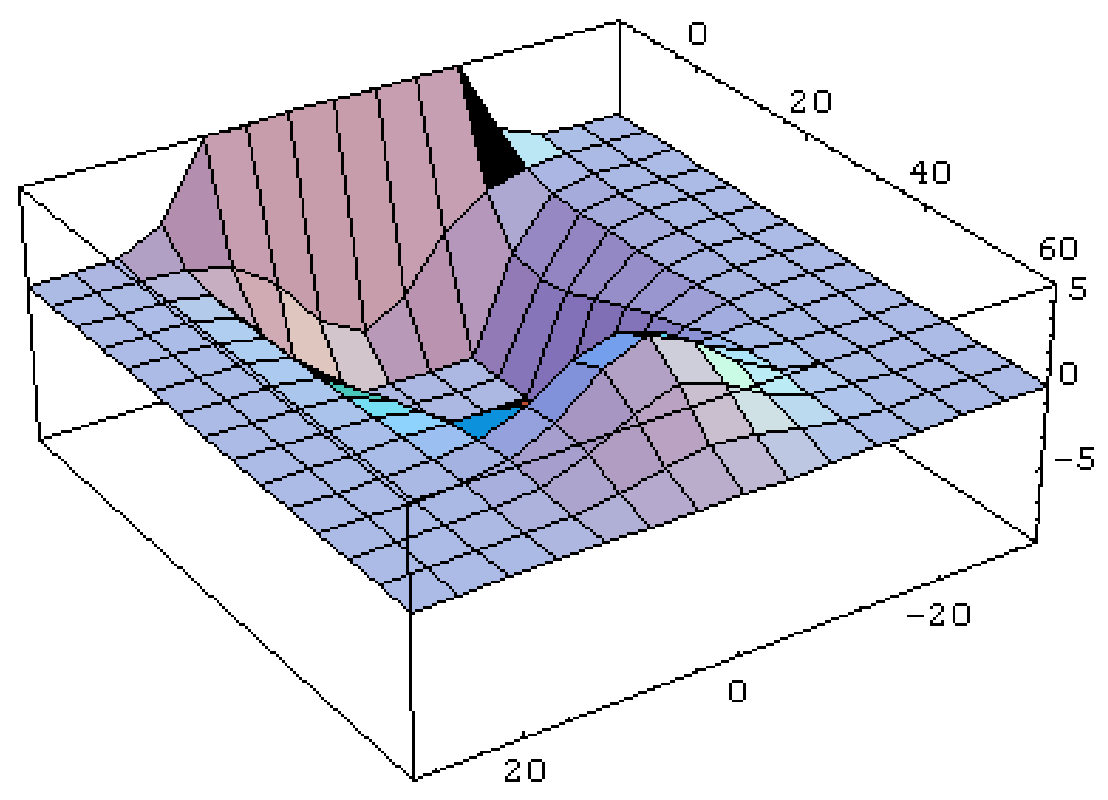

Figure 4. 3D plot of potential energy for the interaction of $\mathrm{H}_{2}$ and $(\mathrm{H}+\mathrm{H})$ with the active center on the metallic $(\mathrm{Pd}$ or $\mathrm{Cu})$ surface.

wells with a more pronounced barrier. The dissipation of energy after adsorption was taken into account by introducing the damping factor within the well near the surface. The reverse process of desorption has been simulated by supplying some correlated subsequent impulses of force to the captured atoms in the wells. As a result of calculations the trajectories of the atoms have been obtained. Moreover, the program provided a comprehensive visualization of the simulated processes. There are some interesting points proved to be revealed.

1. In the case when only $\mathrm{Pd}$ atoms are present at the surface and their d-orbitals are normally oriented, the geometric factor (i.e. the correspondence of the bond length in the molecule and the distance between d-orbitals ) is the most important.

If d-orbitals of the Pd atoms are normally oriented, a very low potential barrier does not prevent the $\mathrm{H}_{\mathrm{a}}$ to get into the well in the case of dissociation. In the classic model used here, dissociation takes place due to separation of atoms by potential wells. The success of this process depends on the degree of vibrational excitation of the molecule. The excitation also permits us to approximately simulate the role of electronic excitation in decomposition (due to the electron transition to the antibonding orbital of the molecule).

2. In the case of declined d-orbitals, the geometric factor became more favourable. Besides, some "easy way" through the barrier appears (figure 3b.B). Along this path in the saddle point the molecule is subjected to a strong deformation which is useful for the subsequent dissociation.

3. Due to the specific local atomic arrangement on $\mathrm{Cu}_{3} \mathrm{Pd}$ surface, when each 
$\mathrm{Pd}$ atom is surrounded by $\mathrm{Cu}$ atoms, the symmetry considerations make it possible to conclude that d-orbitals of $\mathrm{Pd}$ are more or less normally oriented. Geometric factor here is very unsuitable: $\mathrm{Pd}-\mathrm{Pd}$ distance is about two times higher than for pure palladium. In this case, however, dissociation is stimulated by the action of the potential barrier of copper.

4. For $\mathrm{CuPd}$ surface, declined $\mathrm{Pd}$ bonds are more probable and geometric factor is more favourable than in the previous case. Simulations reveal in this case the enhanced dissociation due to cumulative action of both copper barrier and $\mathrm{Pd}$ wells. As a result the hydrogen atoms prove to be bonded not with the neighbour surface $\mathrm{Pd}$ atoms but with the more distant ones. Therefore, the reverse process of quick correlated desorption became forbidden and such an important microscopic parameter as $c_{k} / d_{k}$ in (1) should be effectively increased, leading both to an increase of catalytic yield in the case of catalysis and the sensitivity in the case of gas detection. The respective experimental data are presented below.

\section{Some experimental data}

According to the principles of MIS gas sensors operation outlined in the previous section, an exposition of the external surface of the active layer with $\mathrm{H}_{2}$ molecules leads to internal adsorption of atomic hydrogen at the metal-dielectric interface and to the shift of flat-band voltage $\left(\Delta \mathrm{V}_{\mathrm{FB}}\right)$ of the MIS structure. The response of the sensor i.e. $\Delta \mathrm{V}_{\mathrm{FB}}(\mathrm{t})$ value as a function of time of the exposition obtained from $\mathrm{C}(\mathrm{V})$ measurements, may be compared with the theoretical calculations based on the solution of the system (1) and (2). In our experiments the Pd film (field electrode) was deposited by magnetron deposition up to thickness $50 \mathrm{~nm}$. In some cases Pd was covered by ultra-thin $(5 \mathrm{~nm})$ and probably, initially discontinuous, copper layer. During preparation of the samples, $\mathrm{Cu}$ atoms penetrated into the subsurface of Pd layer to the depth of $5 \mathrm{~nm}$. As a result, a homogeneous (SEM data) surface alloy $\mathrm{Cu}_{\mathrm{x}} \mathrm{Pd}$ with the composition of about $\mathrm{x}=1$ (AES data) is formed. The typical responses of the sensors on $\mathrm{H}_{2}$ pulse followed by an oxygen pulse are shown in figure 5. The parameters of the responses of the field-effect gas sensors $\mathrm{Pd}-\mathrm{Si}_{3}-\mathrm{N}_{4}$ $\mathrm{SiO}_{2}-\mathrm{Si}$ and $\mathrm{Cu} / \mathrm{Pd}-\mathrm{Si}_{3}-\mathrm{N}_{4}-\mathrm{SiO}_{2}-\mathrm{Si}$ are demonstrated in table 1.

The maximum response value (besides partial pressure of $\mathrm{H}_{2}$ ) depends directly on two microscopic parameters: (i) the number of catalytically active centers and (ii) on $c_{k} / d_{k}$ ratio for the detected molecules (see above). Other parameters of the response (figure 5), namely, the time of the response $\tau_{1}$ (after the beginning of exposition) and the times of the recovery $\tau_{2}$ (after the end of gas pulse) depend on the bulk transport properties of the metallic layer as well.

In this table the averaged data for 5 samples and respective measurement regimes are presented. The characteristics were measured both for "as prepared" sensors, and after their thermal treatment in the dry air gas environment. The comparison can be summarized as follows: 


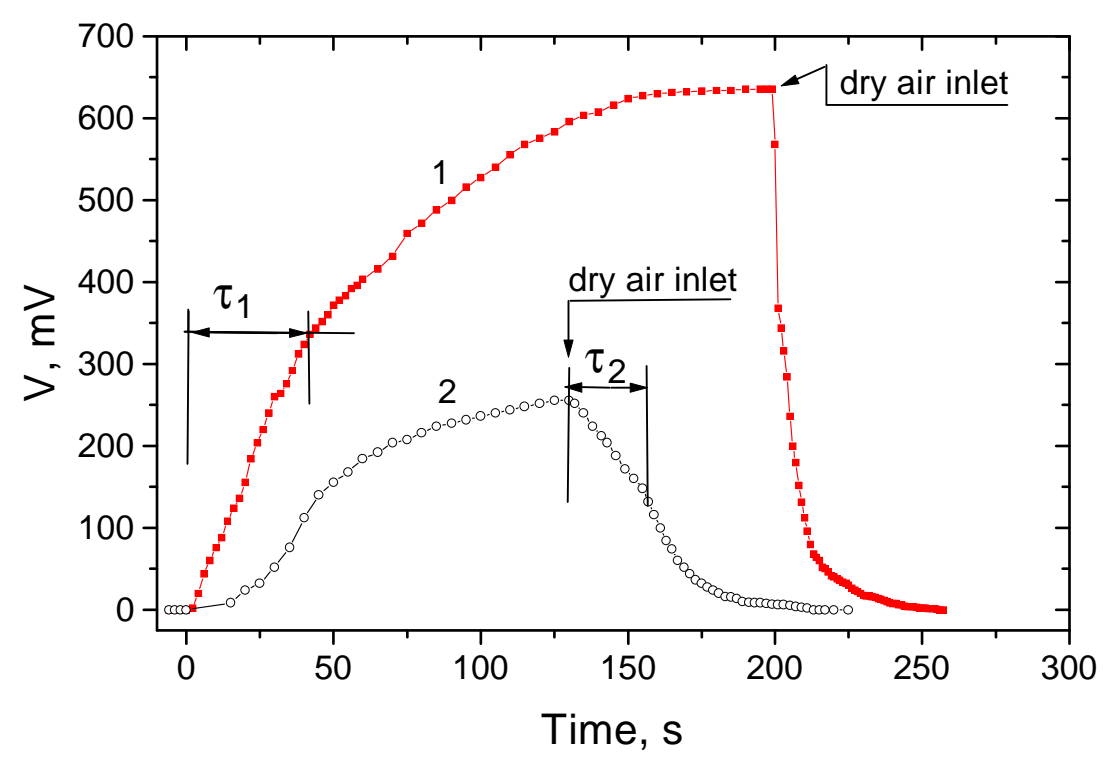

Figure 5. Transient responses of freshly prepared MIS structures with $\mathrm{Pd} / \mathrm{Cu}$ (1) and $\operatorname{Pd}(2)$ electrodes on hydrogen pulse $(500 \mathrm{ppm})$ followed the air pulse (1 atm). $\tau_{1}$ and $\tau_{2}$ are the characteristic times of the response and recovery, correspondingly.

1. The value of $\Delta \mathrm{V}_{\mathrm{FB}}$ for systems with surface $\mathrm{Cu} / \mathrm{Pd}$ composite, indicates their higher catalytic activity $\left(\Delta \mathrm{V}_{\mathrm{FB}}\right.$ larger on $\left.10-20 \%\right)$, than for the systems with pure Pd surface.

2. After "aging" heat treatments these differences become even more pronounced (30-40\%). i.e., more noticeable catalytic enhancement takes place after $\mathrm{CuPd}$ surface alloy formation.

3. Time of the response is systematically smaller (but not so noticeable) for MIS structures with a surface alloy. On the other hand, times of recovery are remarkably smaller for $\mathrm{Pd} / \mathrm{Cu}$ surface. Therefore, more enhanced reaction between atomic hydrogen and oxygen (accompanied by $\mathrm{H}_{2} \mathrm{O}$ desorption) takes place in this case.

4. The fact of a more intensive reaction with hydrogen shows that interaction of oxygen with substrate atoms proper on $\mathrm{CuPd}$ surface is more weak. Indeed, these structures proved to be more stable and resistant against "aging" heat treatments as well (see table 1).

\section{Conclusion}

We would like to emphasize in conclusion that the qualitative conception of describing the chemical bonds, based on the atomic d-orbitals characterization, can be used to predict some general regularities of dissociative adsorption and catalysis on 
Table 1. Parameters of the $\mathrm{Pd}-\mathrm{Si}_{3}-\mathrm{N}_{4}-\mathrm{SiO}_{2}-\mathrm{Si}$ and $(\mathrm{Pd} / \mathrm{Cu})-\mathrm{Si}_{3}-\mathrm{N}_{4}-\mathrm{SiO}_{2}-\mathrm{Si}$ sensors annealed at $150^{\circ} \mathrm{C}$

\begin{tabular}{|c|l|c|c|c|c|}
\hline NN & $\begin{array}{l}\text { Parameter } \\
\text { (average) }\end{array}$ & $\begin{array}{l}\text { Pd sensor } \\
\text { (initial) }\end{array}$ & $\begin{array}{l}\text { Pd sensor } \\
\text { (annealed) }\end{array}$ & $\begin{array}{l}\text { Pd/Cu sensor } \\
\text { (initial) }\end{array}$ & $\begin{array}{l}\text { Pd/Cu sensor } \\
\text { (annealed) }\end{array}$ \\
\hline 1 & $\begin{array}{l}\text { Sensitivity } \\
\text { VFB (mV) }\end{array}$ & 500 & 400 & 550 & 570 \\
\hline 2 & $\begin{array}{l}\text { Time of re- } \\
\text { sponse (s) }\end{array}$ & $5-35$ & 20 & 25 & 15 \\
\hline 3 & $\begin{array}{l}\text { Time of re- } \\
\text { covery (s) }\end{array}$ & 45 & 10 & 5 & 2 \\
\hline
\end{tabular}

the surface of alloys. The most important factors, which effect the peculiarities of these bonds are (i) type of crystalline structure of the surface in close vicinity to the active centers, in particular, the local symmetry of atomic arrangement, (ii) intrinsic defects, and (iii) type, number (symmetry) and electronegativity of foreign atoms present in the neighbourhood of the atoms of d-element. The factors (i)-(iii) act on the three most critical parameters of surface dangling bonds such as orientation, directness, and length. These parameters in their turn determine the characteristics of a potential barrier and a well of an adsorption center. Computer simulation of adsorption-desorption processes based on this approach has enabled us to study the catalytic properties of $\mathrm{Cu}_{\mathrm{x}} \mathrm{Pd}$ alloy surface relating to the dissociative adsorption of hydrogen-containing molecules as well as to explain the enhancing action of copper on this process. This direct simulation together with a computer modelling of MIS gas sensor operation (based on more phenomenological approach) gives us also a possibility to explain the experimental data, demonstrating the increase of the catalytic activity of $\mathrm{CuPd}$ surface as to $\mathrm{H}_{2}$ decomposition (in comparison with a pure $\mathrm{Pd})$ in MIS gas sensors.

\section{Acknowledgements}

This work was performed within the framework of research and development project 01RS9604/8 between TU Ilmenau, Germany and ISP NAS of Ukraine.

\section{References}

1. Krylov O.V, Kiselev V.F. Adsorption and Catalysis on Transition Metals and Their Oxides. Berlin-Heidelberg, Springer Verlag, 1989.

2. Litovchenko V.G., Efremov A.A., Gorbanyuk T.I., Lisovskii I.P., Schipanski D., Gerginchev Z., Kornezky P. // Phys. Low. Dimensional structures, 1995, vol. 12, p. $193-202$.

3. Tompkins F.C. Heterogeneous catalysis. - In: Surface Science: Recent Progress and Perspectives (ed. by T.S. Jayadevaiah and R. Vanselow), CRC Press Inc., 1974, p. 235284. 
4. Gomer R. Some aspect of the chemisorption theory. - In: Surface Science: Recent Progress and Perspectives (ed. by T.S. Jayadevaiah and R. Vanselow), CRC Press Inc., 1974, p. 189-200.

5. Zangwill A. Physics at Surfaces. Cambridge-New York, Cambridge University Press, 1988.

6. Holst B., Nohlen M., Wandelt K., Allison W. The growth of ultra-thin Cu films on Pt (111), probed by helium atom scattering and scanning tunnelling microscopy. // Surf. Science, 1997, vol. 377-379, p. 891-894

7. Belkhou R., Thiele J., Guilot C. Growth of $\mathrm{Pt} / \mathrm{Cu}(100)$ : formation of surface alloy. // Surf. Science, 1997, vol. 377-379, p. 948-952.

8. Hermann P., Tardy B., Simon D. // Surf. Science, 1994, vol. 307-309, p. 422-427.

9. Castro G.R., Doyen G. Electronical and structural effects in CO chemisorption on $\mathrm{Cu}_{3} \mathrm{Pt}$ (111). // Surf. Science, 1994, vol. 307-309, p. 384-389.

10. Linke R., Schneider U., Busse H., Becker C., Schroder U., Castro G.R., Wandelt K. Interaction of hydrogen with $\mathrm{Cu}_{3} \mathrm{Pt}$ (111): dissociation via isolated platinum atoms // Surf. Science, 1994 vol. 307-309, p. 407-411.

11. Litovchenko V.G., Lisovskii I.P., Efremov A.A., Gorbanyuk T.I., Schipanski D., Gerginchev Z., Kornetzky P. About nature of adsorboelectric effect in $\mathrm{Pd}-\mathrm{Si}_{3} \mathrm{~N}_{4}-\mathrm{SiO}_{2-}$ Si under adsorption of hydrogen molecules. // Poverkhnost', 1995, vol. 11, p. 5-16 (in Russian).

\section{Підсилена каталітична дисоціація адсорбованого водню, що містить молекули}

\section{В.Г.Литовченко, А.А.Єфремов}

Інститут фізики напівпровідників НАН України, 252028 Київ, проспект Науки, 45

Отримано 21 квітня 1998 р.

Аналізуються деякі загальні концепції і механізми дисоціативної адсорбції і каталізу. Обговорюється роль таких факторів, як конфігурації електронних оболонок ізольованих атомів, кристалічна структура поверхні, локальні структурні нерегулярності, орієнтація поверхневих зв'язків, ефекти розмірності, присутність чужорідних атомів у локальному атомному оточенні, а також роль локальної симетрії центра адсорбції. Ці обговорення використовуються при розвитку програми для комп'ютерного моделювання процесу. Каталітичні властивості поверхневих сплавів $\mathrm{PdCu}_{x}$ аналізуються, використовуючи комп'ютерне моделювання, і отже, передбачено підсилення дисоціативної адсорбції $\mathrm{H}_{2}$ для такої системи. Представлені експериментальні дані, які демонструють підсилення чутливості сенсора метал-ізолятор-напівпровідник з електродом CuPd у порівнянні з чистим електродом Рd.

Ключові слова: дисоціативна адсорбція, комп'ютерне моделювання, каталіз, виявлення газу, поверхневі сплави

PACS: 82.65.Jv, 82.20.W, 82.30.Nr, 33.15.F 